\title{
Methicillin-Resistant Staphylococcus aureus Acute Keratitis After Intracorneal Ring Segment Implantation
}

\author{
Gonzalo García de Oteyza (1) - Andrea Laiseca - Paola Sauvageot • \\ Juan Álvarez de Toledo
}

Received: July 4, 2017 / Published online: August 14, 2017

(c) The Author(s) 2017. This article is an open access publication

\section{ABSTRACT}

Introduction: The purpose of this study was to report the first case of acute bacterial keratitis produced by methicillin-resistant Staphylococcus aureus after the implantation of two intracorneal ring segments during an uneventful procedure for treating keratoconus in a 13year-old child.

Case Report: A patient with grade III keratoconus underwent an implantation of intracorneal ring segments with no complications during the procedure. Three days later, a whitish corneal infiltrate appeared in between the union of both corneal rings. Sample cultures were positive for methicillin-resistant $S$. aureus (MRSA). Corneal infiltrate did not improve despite intensive topical and systemic antibiotics. Melting appeared even after the explantation of both corneal rings. Keratoplasty $\grave{a}$ chaud had to be performed to preserve the eye integrity.

Conclusions: MRSA keratitis following intracorneal ring segment implantation is a rare but

Enhanced content To view enhanced content for this article go to http://www.medengine.com/Redeem/ 947AF0606C80FE82.

G. García de Oteyza $(\bowtie) \cdot$ A. Laiseca · P. Sauvageot . J. Álvarez de Toledo

Department of Cornea and Ocular Surface, Centro de Oftalmología Barraquer, Barcelona, Spain e-mail: gonzalo_gdeoteyza@hotmail.com severe complication that can lead to a therapeutic penetrating keratoplasty to definitely cure the process.

Keywords: Acute keratitis; Complication; Intracorneal segment ring; Keratoconus; MRSA

\section{INTRODUCTION}

In the past century, penetrating keratoplasty (PK) was the one and only procedure to treat patients with keratoconus. Fortunately, nowadays the treatment of keratoconus has multiple options. Different techniques have improved in the last decade, thereby reducing the need for a corneal graft. In early stages of keratoconus, we may use gas-permeable contact lens, corneal cross-linking, or even intracorneal segment rings (ICSR). The use of ICSR has been increasing since Colin [1] first reported its efficacy.

ICSR were first approved to correct low myopia. Years later the refractive procedure switched to an orthopedic one. The use of ICSR for keratoconus, pellucid marginal degeneration, or post-LASIK ectasia is widely accepted. Reversibility, adjustability, and the fact that the center of the cornea is left untouched are the main advantages of this procedure [2].

Although rare, complications like extrusion of the ring, neovascularization, corneal haze, corneal melting, and infectious keratitis have been described after ICSR implantation [3]. We 
report the first case of methicillin-resistant Staphylococcus aureus (MRSA) acute keratitis after ICSR implantation aided by femtosecond laser in a child.

\section{CASE REPORT}

A 13-year-old boy presented with bilateral and asymmetrical keratoconus relating to a 3-year history of blurred vision. The best-spectacle corrected visual acuity (BSCVA) of the right eye (RE) was $20 / 25\left(+0.25-1.50 \times 95^{\circ}\right)$, the maximum keratometry $\left(K_{\max }\right)$ was 43.8 diopter $(D)$, and the thinnest pachymetry was $573 \mu \mathrm{m}$. The BSCVA of the left eye (LE) was 20/400 $\left(-3.0\right.$ to $\left.3.0 \times 160^{\circ}\right), K_{\max }$ was $59.8 \mathrm{D}$, and the thinnest pachymetry was $504 \mu \mathrm{m}$. The patient did not tolerate the test with gas-permeable contact lens.

The implantation of intracorneal ring segments (ICRS) was performed, after informed consent was obtained from the patient and his parents, on the LE in order to regularize the shape of the cornea and decreasing corneal aberrations. Femtosecond laser (Visumax $^{\circledR}$ Zeiss) was used to create the intrastromal channel. Two Ferrara rings of $160^{\circ}$ (AJL Ophthalmic S.A., Spain) were implanted at $400-\mu \mathrm{m}$ corneal depth by using an incision at $65^{\circ}$.

One day after the implantation, the BSCVA was $20 / 200$ and the $K_{\max }$ was $52.5 \mathrm{D}$. No other findings on the slit-lamp examination were reported (Fig. 1).

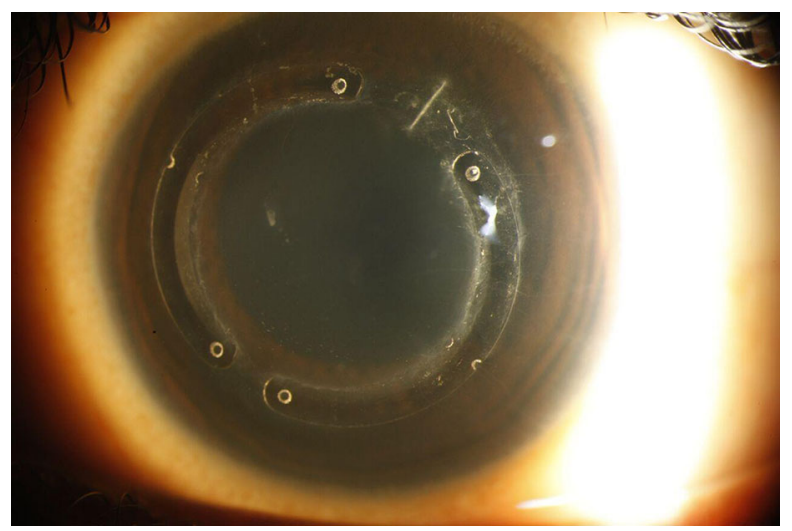

Fig. 1 Day 1 slit-lamp examination after the implantation of ICRS
Seventy-two hours after the procedure, the patient presented with hyperemia and ocular pain. A whitish infiltrate appeared in the inferior union of both rings. Anterior chamber reaction was mild but no hypopyon was present at that time. Corneal curettage samples were collected for stain and culture. Topical treatment with hourly fortified antibiotics was started (vancomycin $50 \mathrm{mg} / \mathrm{mL}$ and ceftazidime $50 \mathrm{mg} / \mathrm{mL}$ ). On day 4 , the infiltrate grew and a $5-\mathrm{mm}$ hypopyon appeared. The patient was hospitalized to explant the ICRS and irrigate the ring channels with vancomycin and moxifloxacin. Intravenous vancomycin $350 \mathrm{mg}$ every $8 \mathrm{~h}$ was started.

Cultures came back positive for methicillin-resistant $S$. aureus.

One day after the explantation, the hypopyon level was higher and an intense corneal melting was present (Fig. 2). An 8.5-mm keratoplasty à chaud had to be performed to save the integrity of the globe. Ten days after the surgery the corneal graft was clear with no signs of infection. Tobramycin $(3 \mathrm{mg} / \mathrm{mL})$ and dexamethasone $(1 \mathrm{mg} / \mathrm{mL}$ ) eye drops (Tobradex; Alcon Cusí S.A., Barcelona, Spain) five times daily were started. The patient was allowed to return to his country of origin but presented 4 months later with a marked corneal edema and all the stitches were loose (Fig. 3a). One month later a new penetrating keratoplasty was performed and the patient now has a transparent graft (Fig. 3b).

\section{DISCUSSION}

Infectious keratitis is a rare complication after the implantation of ICRS. Despite its low frequency it can be a serious and sight-threatening event when it occurs. Coskunseven et al. [4] reported the largest series of complications after the implantation of ICRS aided with femtosecond laser. Only one patient of those 850 presented with an infectious keratitis (0.1\%). Other authors like Shabayek and Alió [5] reported an incidence of $4.8 \%$. Most of the reported cases are adults. Cases in children are extremely rare. Mulet et al. [2] indicates that ring implantation using a femtosecond laser is safer than using a 

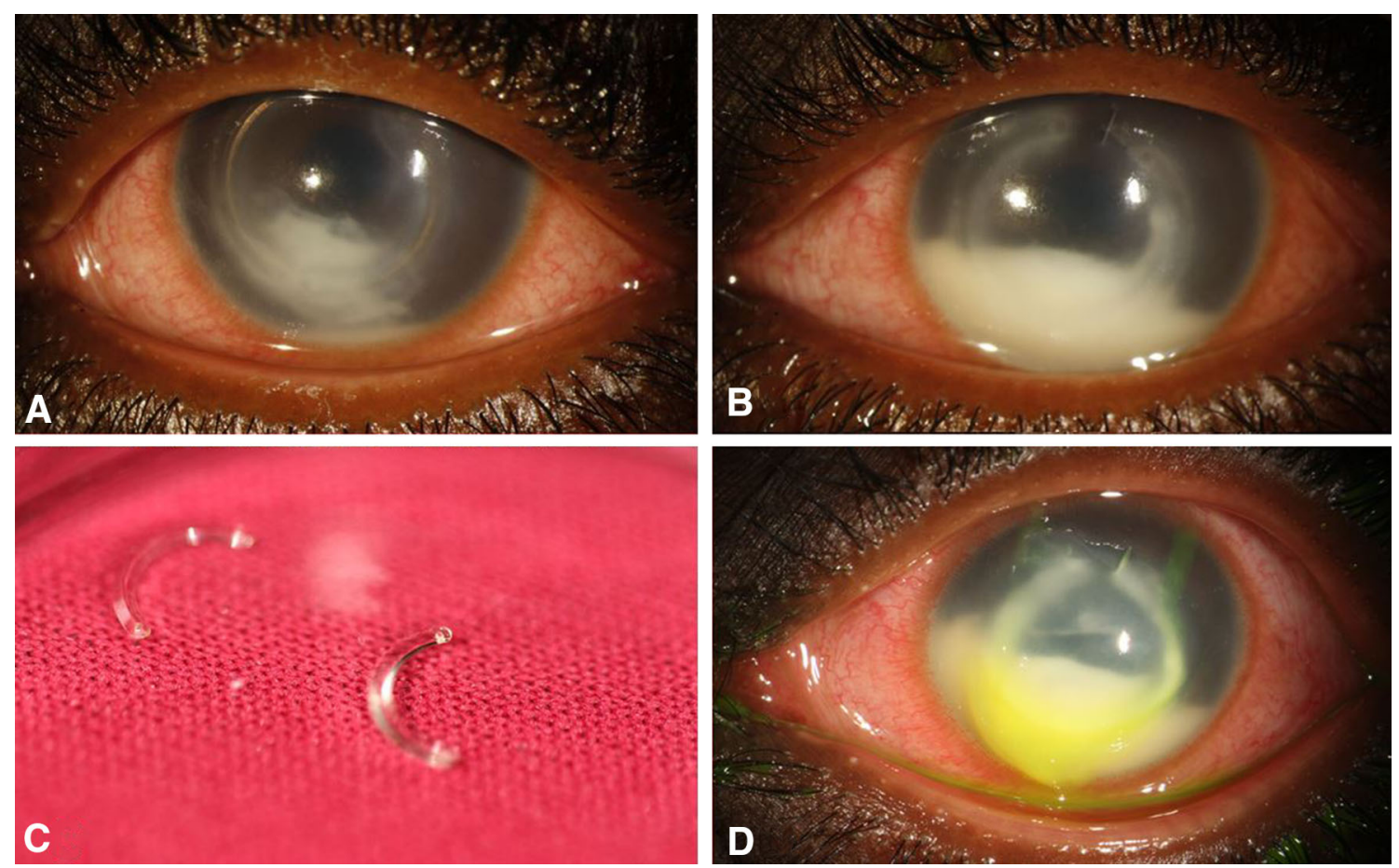

Fig. 2 Evolution of the case. a Day 3 after ICSR implantation. A whitish corneal infiltrate appeared in the inferior union of both rings. b Day 4 after ICSR

implantation. A 5-mm hypopyon is present. c Explanted ISCR. d Day 1 after the explantation. Corneal melting and 6-mm hypopyon
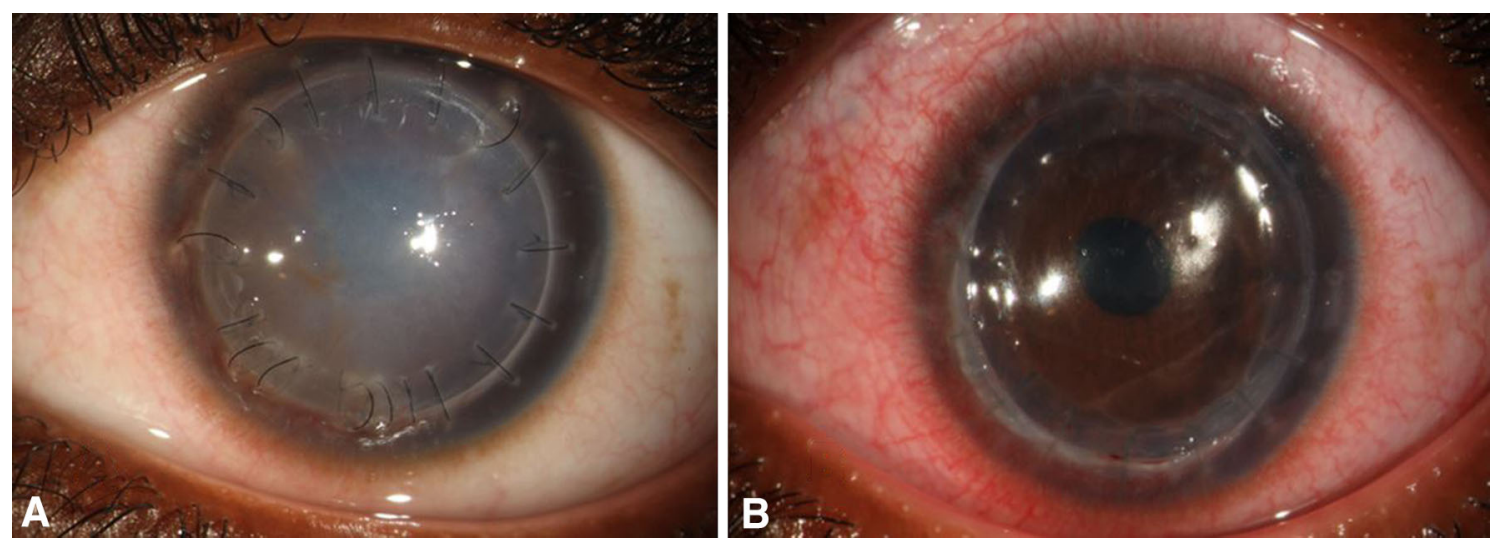

Fig. 3 a Four months after therapeutic penetrating keratoplasty. Corneal edema and loose stitches. b Second penetrating keratoplasty

manual technique. Other publications suggest that there is no significant difference between both techniques [6].

Multiple microorganisms have been reported in the context of this complication. Both bacteria and fungi can produce an infectious keratitis. However, S. aureus is the most common microorganism reported [6]. Different risk factors have been reported such as contact lens misuse, diabetes, loose sutures, trauma, and atopic blepharoconjunctivitis. In this case, the patient was constantly rubbing his eye, which is another well-described risk factor. The use of a Ferrara ring seems to increase the incidence of 
infectious keratitis as a result of its triangular shape and higher risk of extrusion [6]. It is important to try to prevent those risk factors, treating any kind of pathology before implanting the ring and also educating the patient by explaining the risk behaviors.

Topical antibiotic therapy is the most extensive way of treating infectious keratitis after ICRS implantation. Bourcier et al. [7] reported that the use of topical antibiotics alone was enough to treat the infection. On the other hand, ring removal is considered in some publications as the first therapeutic option to treat this complication. Hofling-Lima et al. [8] reported, as in this case, the need to perform penetrating keratoplasty à chaud to control the infection in two patients out of eight.

Therapeutic keratoplasty (TKP) is indicated in cases with progressive ulceration despite maximum antibacterial medication, extensive corneal involvement, descemetocele, or high risk of perforation. TKP has an incidence of $3-6 \%$ in bacterial corneal ulceration [9]. This procedure has a definitive role in the management of progressive microbial keratitis refractory to medical therapy and offers a cure rate up to $100 \%$ in bacterial and fungal keratitis [10]. Methicillin-resistant $S$. aureus is a rare microorganism that can cause an infectious keratitis after ICRS implantation for keratoconus, an acute and serious complication that can lead to therapeutic keratoplasty to save the eye integrity.

In conclusion, we recommend a strict follow-up of patients with risk factors and ICRS implantation for keratoconus to try to prevent such a severe keratitis. Educating the patients about avoidable risk factors and alarm symptoms may help to prevent and detect this severe complication early.

\section{ACKNOWLEDGEMENTS}

No funding or sponsorship was received for this study or publication of this article. The article processing charges were funded by the authors. All named authors meet the International Committee of Medical Journal Editors (ICMJE) criteria for authorship for this manuscript, take responsibility for the integrity of the work as a whole, and have given final approval for the version to be published.

Disclosures. Gonzalo García de Oteyza, Andrea Laiseca, Paola Sauvageot, and Juan Álvarez de Toledo have nothing to disclose.

Compliance with Ethics Guideslines. Informed consent was obtained from the patient and his parents.

Data Availability. Data sharing is not applicable to this article as no datasets were generated or analyzed during the current study.

Open Access. This article is distributed under the terms of the Creative Commons Attribution-NonCommercial 4.0 International License (http://creativecommons.org/licenses/ by-nc/4.0/), which permits any noncommercial use, distribution, and reproduction in any medium, provided you give appropriate credit to the original author(s) and the source, provide a link to the Creative Commons license, and indicate if changes were made.

\section{REFERENCES}

1. Colin J, Cochener B, Savary G, Malet F. Correcting keratoconus with intracorneal rings. J Cataract Refract Surg. 2000;26:1117-22.

2. Mulet ME, Pérez-Santonja JJ, Ferrer C, Alió JL. Microbial keratitis after intrastromal corneal ring segment implantation. Refract Surg. 2010;26:364-9.

3. Ferrer C, Alió JL, Uceda Montañés A, et al. Causes of intrastromal corneal ring segment explantation: clinicopathologic correlation analysis. J Cataract Refract Surg. 2010;36(6):970-7.

4. Coskunseven E, Kymionis GD, Tsiklis NS, et al. Complications of intrastromal corneal ring segment implantation using a femtosecond laser for channel creation: a survey of 850 eyes with keratoconus. Acta Ophthalmol. 2011;89:54-7.

5. Shabayek MH, Alió JL. Intrastromal corneal ring segment implantation by femtosecond laser for 
keratoconus correction. Ophthalmology. 2007;114(9):1643-52.

6. Levy J, Lifshitz T. Keratitis after implantation of intrastromal corneal ring segments (Intacs) aided by femtosecond laser for keratoconus correction: case report and description of the literature. Eur J Ophthalmol. 2010;20(4):780-4.

7. Bourcier $\mathrm{T}$, Borderie $\mathrm{V}$, Laroche L. Late bacterial keratitis after implantation of intrastromal corneal ring segments. J Cataract Refract Surg. 2003;29:407-9.
8. Hofling-Lima AL, Branco BC, Romano AC, et al. Corneal infections after implantation of intracorneal ring segments. Cornea. 2004;23:547-9.

9. Sony P, Sharma N, Vajpayee RB, Ray M. Therapeutic keratoplasty for infectious keratitis: a review of the literature. CLAO J. 2002;28(3):111-8.

10. Killingsworth DW, Stern GA, Driebe WT, et al. Results of therapeutic penetrating keratoplasty. Ophthalmology. 1993;100(4):534-41. 